\title{
New quality index based on dry matter and acidity proposed for Hayward kiwifruit
}

\author{
by Gayle M. Crisosto, Janine Hasey, Jorge A. \\ Zegbe and Carlos H. Crisosto
}

Researchers from various countries have proposed using dry matter at harvest as a worldwide quality index for Hayward kiwifruit, because it includes both soluble (sugars and acids) and insoluble (structural carbohydrates and starch) solids and doesn't change during postharvest handling. Our consumer tests in 1999 and 2008 indicated that dry matter and ripe titratable acidity are related to in-store consumer acceptance of kiwifruit. In most California seasons, when ripe titratable acidity was less than $1.2 \%$, only a dry matter greater than or equal to $15.1 \%$ was required for consumer acceptability. Our 6-year quality attribute survey of California kiwifruit at harvest and from cold storage demonstrated that dry matter and ripe soluble solids concentration were highly variable among vineyards and seasons, but ripe titratable acidity values varied more among seasons than between vineyards. Our results provide strong evidence that dry matter would be a reliable quality index candidate for California kiwifruit, especially if ripe titratable acidity were factored in.

M easuring the soluble solids concentration of kiwifruit juice at harvest is the official method of assessing its maturity in most kiwifruit-producing countries, including New Zealand, Italy, France, Greece, Chile, Japan and the United States (Beever and Hopkirk 1990; Crisosto and Mitchell 2002). A refractometer is used to make the simple and fast measurement of the concentration of soluble solids such as sugars, organic acids, phenolic compounds and pectins. Minimum harvest maturity standards for Hayward kiwifruit (Actinidia deliciosa [A.

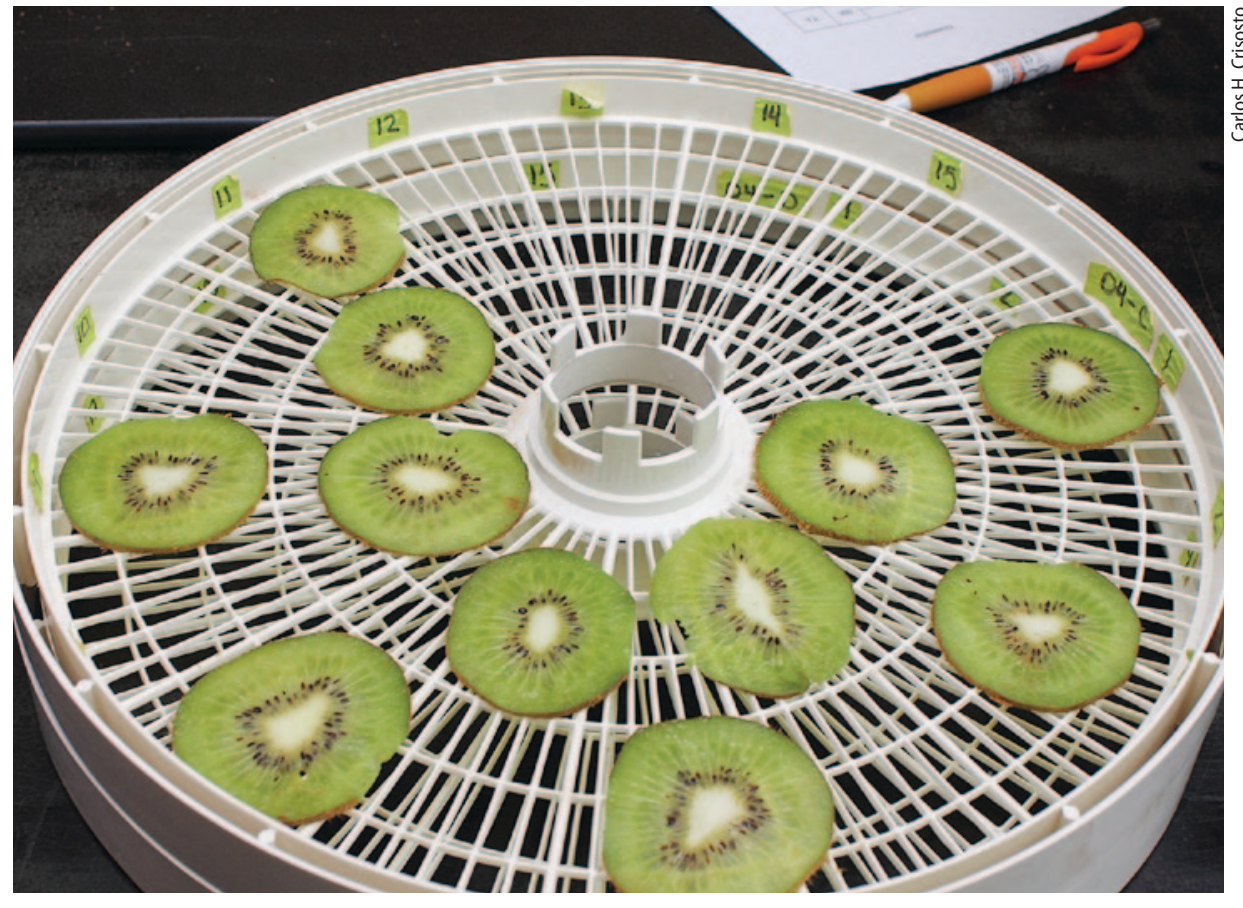

In research analyzing the role of various fruit quality attributes in consumer acceptance, kiwifruit slices were dried in a dehydrator in order to measure dry matter content.

Chev.] C. F. Liang and A. R. Ferguson) are enforced in several countries including the United States, ranging from $5.5 \%$ to $6.5 \%$ soluble solids concentration at harvest (HSSC) (Beever and Hopkirk 1990; Crisosto and Mitchell 2002). This range assures a minimum consumer acceptance (greater than or equal to $12.5 \%$ ripe soluble solids concentration) and adequate storage potential to avoid flesh breakdown, which occurs when soluble solids are less than $6.2 \%$ at harvest (Crisosto and Crisosto 2001).

Kiwifruit is usually harvested when mature but unripe, then kept in cold storage for up to 6 months. Ripening starts at various points in the distribution chain on the fruit's way to the consumer (Ritenour et al. 1999). Ripening time depends on how long the fruit has been stored at $32^{\circ} \mathrm{F}$, and whether it has been preconditioned with ethylene. Kiwifruit harvested with less than $6.2 \%$ soluble solids concentration develop flesh breakdown by 3 months in storage at $32^{\circ} \mathrm{F}$. Soluble solids increase slowly during cold storage as starch is converted to sugars, but the complete conversion occurs when the kiwifruit is ripened.
At harvest, a mature, unripe kiwifruit has a high content of starch and soluble sugars, but soluble solids concentration readings do not take starch into consideration because it is insoluble. Therefore, soluble solids concentration measurements do not accurately predict final soluble sugars after ripening. As ripening and softening progress during the kiwifruit's postharvest life, starch is hydrolyzed to soluble sugars and consequently the soluble solids concentration increases.

The sweetness, eating quality, consumer acceptance and repeat purchases of kiwifruit are strongly associated with the concentration of soluble sugars (Burdon et al. 2004; Crisosto and Crisosto 2001; Harker et al. 2009; Jordan et al. 2000; Rossiter et al. 2000). Following an in-store consumer test, UC researchers proposed a soluble solids concentration after ripening (RSSC) of $12.5 \%$ as the minimum quality index for early-marketed California kiwifruit (Crisosto and Crisosto 2001).

Online: http://californiaagriculture.ucanr.edu/ landingpage.cfm?article $=$ ca.v066n02p70\&fulltext=yes DOI: 10.3733/ca.v066n02p70 
Hayward kiwifruit dominate California production, and they are marketed worldwide. California growers export little, but fruit is shipped to the Southern Hemisphere (New Zealand and Chile) and Italian markets when local crops are out of season, and California receives imports from these countries as well. This globalization has created economic advantages for early- and late-harvest kiwifruit sales, when fruit availability is low and prices are high. However, the incentive to harvest early or to hold fruit in long-term storage can result in low-quality kiwifruit in the market, reducing repeat purchases and overall demand.

To more reliably assure flavor quality, researchers from various countries including New Zealand have proposed, in addition to the harvest maturity index, the use of dry matter concentrations as a voluntary quality index, which would be measured at harvest and/or shipment to market. Dry matter readings include starch and are highly correlated with ripe soluble solids concentration (Beever and Hopkirk 1990; Harker et al. 2009; Jordan et al. 2000), and they do not change during cold storage (Crisosto et al. 2009). New Zealand and Chile have started using a minimum dry matter standard for retail marketing and wholesale trade. However, as yet, there is no agreement on the minimum dry matter level that should be established as a quality index.

To develop a quality index for Hayward kiwifruit, we studied the relationships among dry matter, ripe soluble solids concentration, ripe titratable acidity (RTA) and consumer acceptance. We also investigated dry matter variability in kiwifruit at harvest and from cold storage from several California growing regions, and we surveyed imported kiwifruit during the U.S. low-availability season (March to May and August to November).

\section{In-store consumer survey}

During the 1999 and 2008 kiwifruit growing seasons, we surveyed groups of 142 and 124 consumers, respectively, at a major supermarket in Fresno County. Each consumer was presented with three ripe Hayward kiwifruit samples from California vineyards at targeted dry matter levels (14.0\% to $15.9 \%, 16.0 \%$ to $17.9 \%$ and $\geq 18.0 \%$ ). To ripen the previously coldstored kiwifruit samples (1 to 5 weeks storage at $32^{\circ} \mathrm{F}\left[0^{\circ} \mathrm{C}\right]$ ), cold kiwifruit were exposed to 100 parts per million ethylene for 12 hours, following the preconditioning protocol (Ritenour et al. 1999). This process was carried out 2 to 3 days prior to the consumer test, and the kiwifruit were allowed to ripen at $68^{\circ} \mathrm{F}\left(20^{\circ} \mathrm{C}\right)$ until they reached 2 to 3 pounds-force (1 pound-force equals 4.45 Newtons) flesh firmness (Crisosto and Crisosto 2001).

Flesh firmness and dry matter were measured on the day of the test before the consumers tasted the samples, and juice was extracted from the remaining fruit after tasting on the same day of the test, using previously described methods (Crisosto and Crisosto 2001; Crisosto, Hasey et al. 2008). A kiwifruit sample consisted of a 0.25 -inch-thick slice, halved, cut perpendicular to the long axis of the fruit, adjacent to the location where the slice for dry matter assessment was taken. The consumer responses were recorded using a 9 -point hedonic scale $(1=$ dislike extremely, 9 = like extremely). Consumer acceptance was measured as a degree of liking and expressed as a percentage (Lawless and Heymann 2010).

\section{Fruit quality attributes survey}

During the 2006 and 2007 growing seasons, samples of 10 to 15 kiwifruit, replicated three times, were collected at six different maturity stages (harvest dates) from the same vineyards: three in the San Joaquin Valley (southern region) and three in the Sacramento Valley (northern

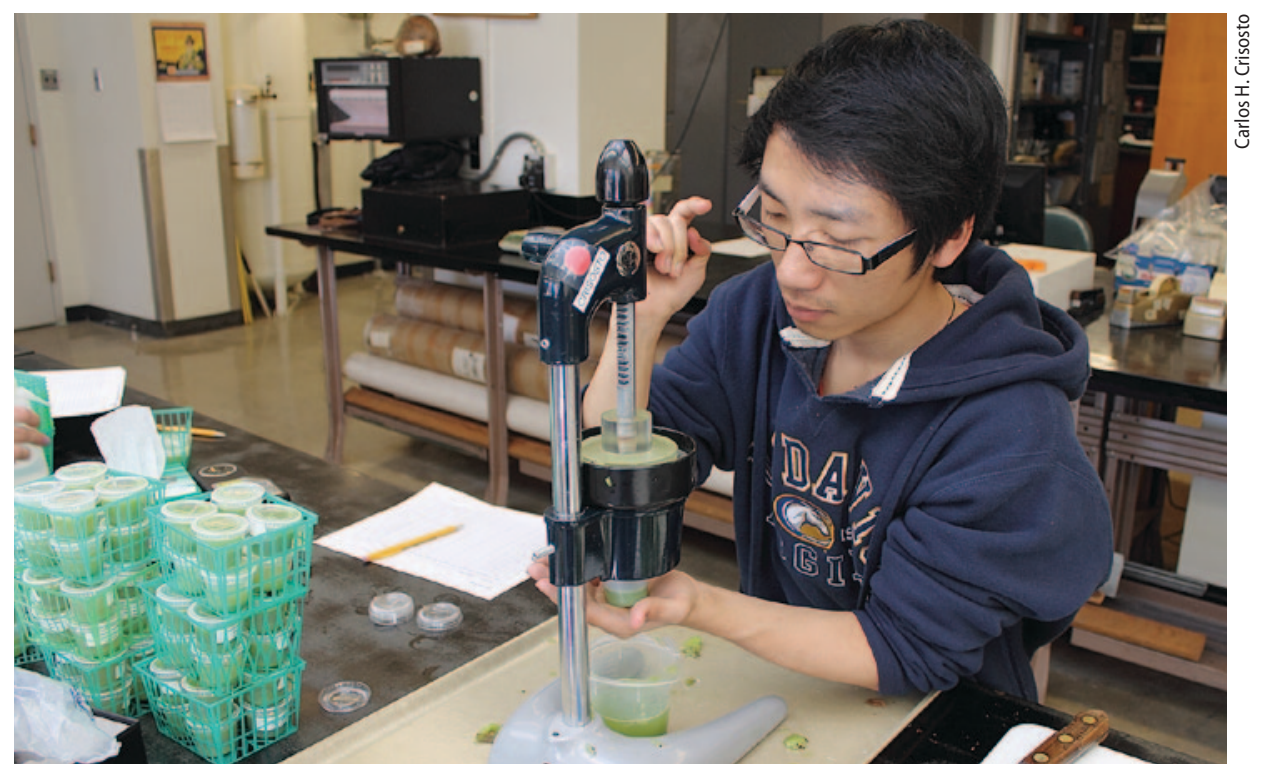

At the F. Gordon Mitchell Postharvest Center in Parlier, UC Davis master's student Jiaxuan Liu juiced kiwifruit collected from vineyards across the Central Valley, as well as imported fruit. region). All kiwifruit samples from these vineyards - and commercial cold-storage facilities and retail stores in California for the low-availability season survey - were immediately transported to the F. Gordon Mitchell

\section{Glossary}

Dry matter: The ratio of the weight of a test sample after drying to the fresh weight of the test sample, expressed as a percentage. Kiwifruit dry matter at harvest is composed of both starch and soluble sugars as well as organic acids, minerals, pectins and other components.

Soluble solids concentration: A measurement consisting primarily of tins, and organic, amino and ascorbic acids. Measured using refractometers or hydrometers.

Starch: A white, tasteless, solid carbohydrate $\left(\mathrm{C}_{6} \mathrm{H}_{10} \mathrm{O}_{5}\right)_{\mathrm{n}}$ occurring in the form of minute granules in seeds, tubers and other parts of plants. Measured by potassium iodide test or other chemical tests.

Titratable acidity: A measure of the total amount of acid present expressed as a percentage of the predominant acid, as determined by titration or chemical tests in a laboratory. soluble sugars, as well as soluble pec- 
Postharvest Center at the Kearney Agricultural Research and Extension Center in Parlier, California, for fruit quality assessments.

Fruit quality attributes measured at harvest included flesh firmness, soluble solids concentration, titratable acidity and dry matter (Crisosto, Hasey et al. 2008). Soluble solids concentration and titratable acidity of ripened fruit were measured as described by Crisosto and Crisosto (2001).

In addition to the vineyard survey, kiwifruit samples of three replicates of 10 to 15 kiwifruit were collected directly from commercial cold-storage facilities in California during 1998, 1999, 2006, 2007, 2008 and 2009 for dry matter determinations. Imported kiwifruit samples from Chile and New Zealand (three replications of 10 kiwifruit) were collected for dry matter determinations directly from California retail stores in 2009 and 2010.

\section{Quality and consumer acceptance}

Dry matter. The in-store consumer tests showed that dry matter content significantly influenced the degree of liking in both seasons (tables 1 and 2). In the 1999 growing season, consumers rated kiwifruit from "like slightly" (6.1) to "like moderately" (7.1). The percentage of consumers who said they "like" (score $>5.0$ ) the kiwifruit varied from $71 \%$ to $87 \%$ depending on dry matter, while the percentage of consumers who chose "dislike" (score < 5.0) ranged between 6\% and $26 \%$. Only a few consumers ( $3 \%$ to $6 \%$ ) chose "neither like nor dislike" (table 1). Degree of liking was significantly higher (6.6 to 7.1) and acceptance was approximately $85 \%$ for

kiwifruit with dry matter greater than or equal to $16.1 \%$ than for kiwifruit with dry matter less than $16.1 \%$.

The in-store consumer test results for the 2008 growing season were similar to the 1999 results (table 1). Consumers rated kiwifruit from "dislike slightly" (4.6) to "like slightly-moderately" (6.5). The percentage of consumers who said they "like" the fruit varied from 35\% to $76 \%$, increasing as dry matter increased, while the percentage who said they "dislike" the fruit decreased from $50 \%$ to $20 \%$ as dry matter increased. "Neither like nor dislike" was chosen by $4 \%$ to $15 \%$ of consumers (table 1).

Ripe titratable acidity. Dry matter and ripe titratable acidity, which is associated with sourness, significantly influenced the degree of liking in the 2008 consumer test, but not in the 1999 test. In 2008, the F-ratio for ripe titratable acidity was significantly higher than for dry matter. (A significant F-ratio means that there is at least one significant difference among

\section{These results demonstrate that consumer acceptance of kiwifruit is affected by dry matter and acidity levels.}

means being compared.) As a result, we divided the data set into two classes for further analysis using dry matter and ripe titratable acidity as combined factors on degree of liking. With the same dry matter levels, one class had a ripe titratable acidity greater than or equal to $1.2 \%$ and the other less than $1.2 \%$ (table 2).

Consumers rated kiwifruit with ripe titratable acidity greater than or equal to $1.2 \%$ from "dislike slightly" (4.4) to "like

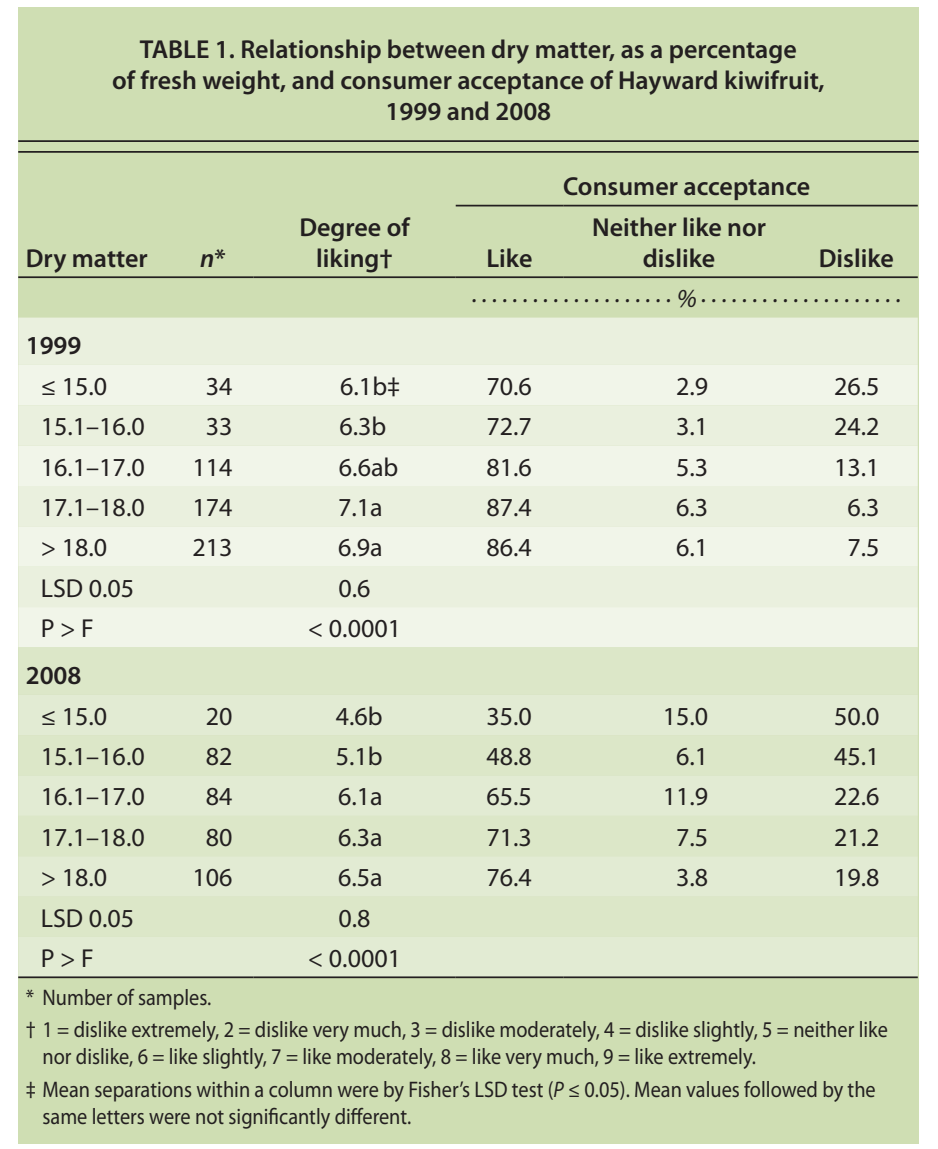

TABLE 2. Consumer acceptance of Hayward kiwifruit at different levels of dry matter, as a percentage of fresh weight, and ripe titratable acidity (RTA), as a percentage of citric acid, 2008

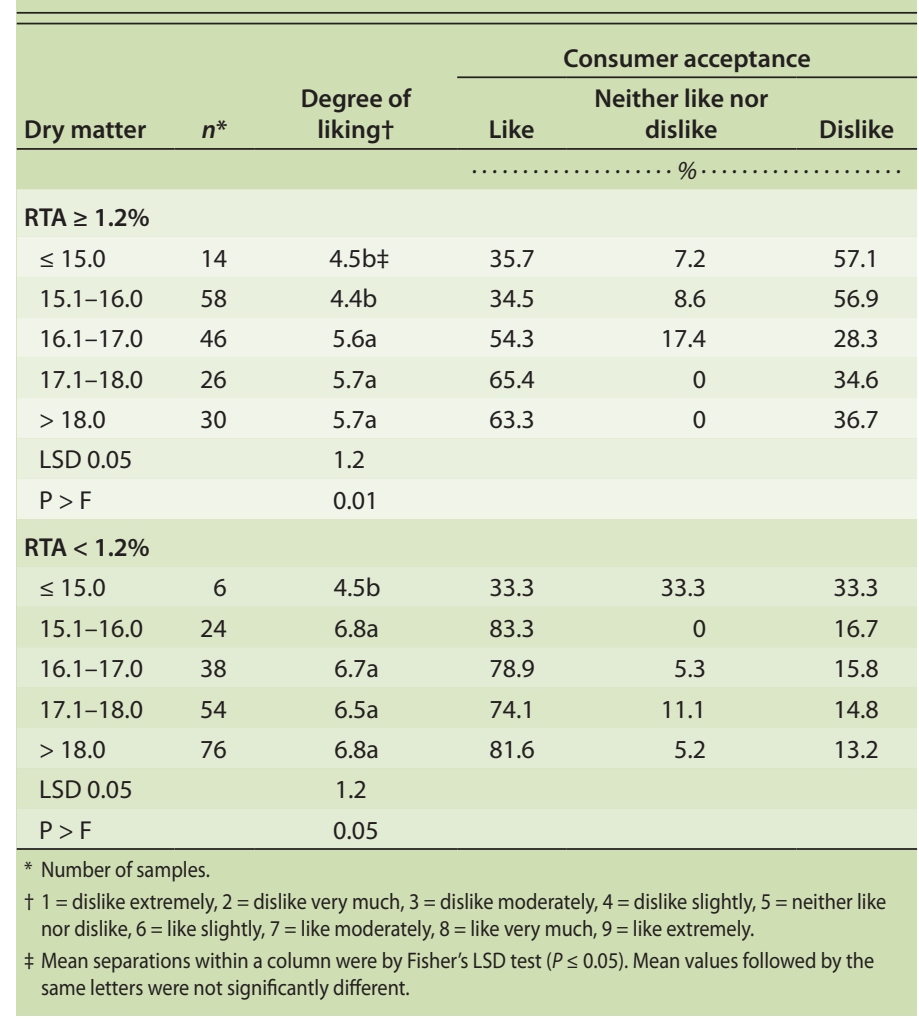


slightly" (5.7), and acceptance ranged from $34 \%$ to $65 \%$. A high percentage of consumers ( $28 \%$ to $57 \%$ ) said they "dislike" these kiwifruit. In this high titratable acidity class, degree of liking was significantly higher for kiwifruit with dry matter greater than or equal to $16.1 \%$ (acceptance ranged from $54 \%$ to $65 \%$ ) than with dry matter less than $16.1 \%$.

Consumers rated kiwifruit with ripe titratable acidity less than $1.2 \%$ from "dislike slightly" (4.5) to "like moderately" (6.8), and acceptance ranged from 33\% to $83 \%$. A high percentage of consumers $(13 \%$ to $33 \%)$ said they "dislike" these kiwifruit. The degree of liking was significantly higher for kiwifruit with dry matter greater than or equal to $15.1 \%$ (acceptance ranged from $74 \%$ to $83 \%$ ). In this class, the percentage of consumers who said they "dislike" the fruit decreased from $33 \%$ to $13 \%$ as dry matter increased. In contrast, consumers who chose "neither like nor dislike" varied among dry matter classes, ranging between $0 \%$ and $33 \%$ (table 2). These results demonstrate that consumer acceptance of kiwifruit is affected by dry matter and acidity levels.

\section{Quality at harvest and after ripening}

2006 samples. In the 2006 growing season, the average dry matter of kiwifruit sampled from the three San Joaquin Valley vineyards (A, B, C) increased from $14.6 \%$ to $16.2 \%$ between Sept. 14 and Oct. 23. During this sampling period, harvest soluble solids concentrations ranged between $5.1 \%$ and $6.6 \%$, and harvest titratable acidity was between $1.8 \%$ and $2.0 \%$. After ripening to a flesh firmness of 2 to 3 pounds-force (9 to 13.5 Newtons), the kiwifruit exhibited average ripe soluble solids concentrations between $10.4 \%$ and $13.1 \%$ and titratable acidity between $0.4 \%$ and $1.1 \%$. (Data in this section is not shown; it is available from authors upon request.)

Minimum quality indexes (dry matter $\geq 15.1 \%$ and soluble solids concentration $\geq 6.2 \%$ ) are important to consider at harvest because they can predict consumer acceptance. For instance, vineyard A reached the minimum dry matter by Sept. 14 and the minimum harvest soluble solids concentration by Oct. 2, with titratable acidity at harvest of $2.0 \%$. However, vineyard A exceeded a ripe soluble solids concentration of $12.5 \%$ by Sept. 25 , and its ripe titratable acidity was lower than

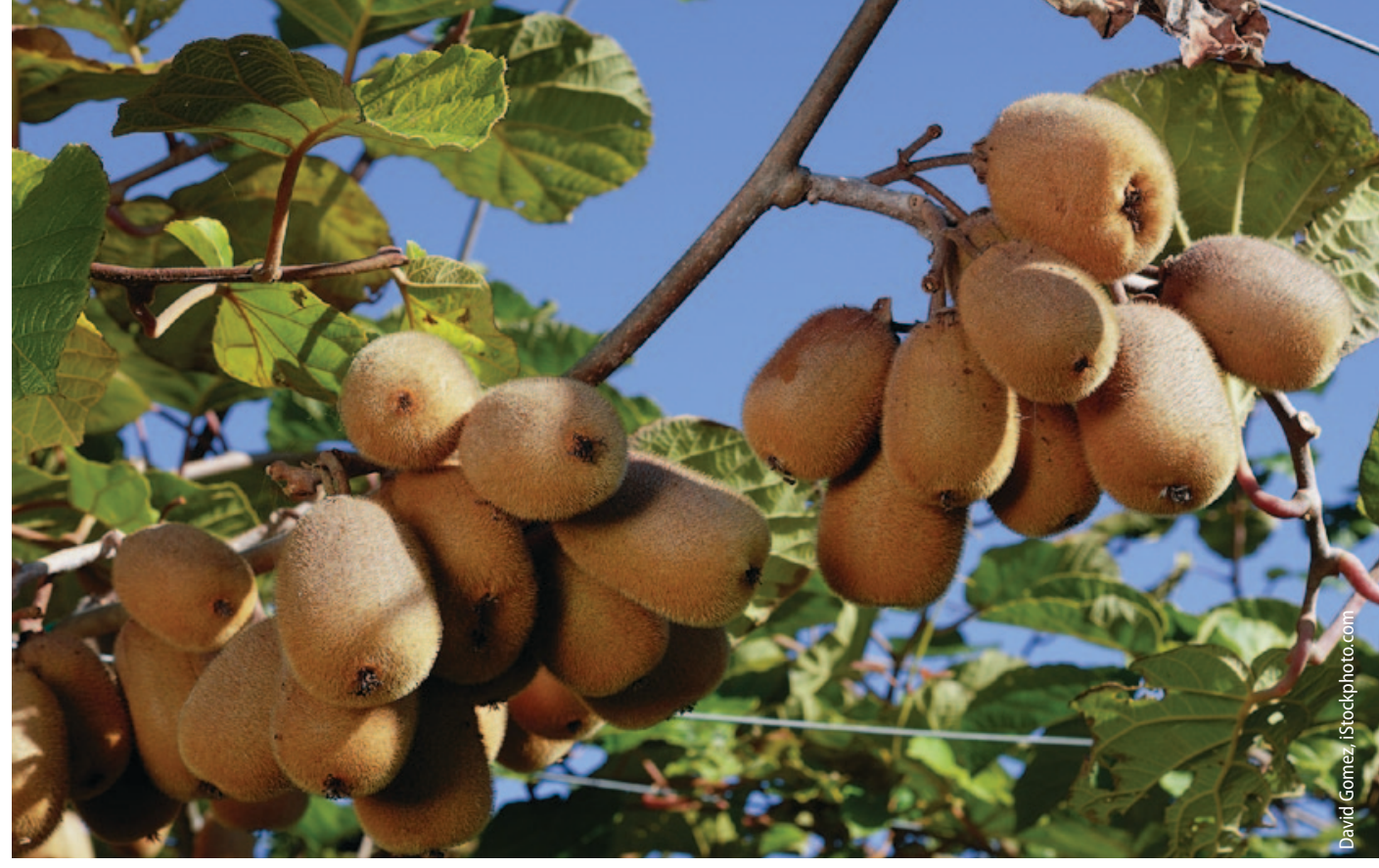

Some 4,200 acres of kiwifruit are harvested annually in California. In this study, dry matter content at harvest, coupled with ripe titratable acidity, was a reliable consumer acceptance indicator.

$1.2 \%$. Vineyard B met the minimum quality indexes at harvest and after ripening in the last harvest (Oct. 23). Vineyard C did not reach the minimum quality indexes during this harvest season.

Average dry matter at harvest of kiwifruit grown in the Sacramento Valley vineyards (D, E, F) increased from 16.1\% to $17.9 \%$ between Sept. 15 and Oct. 23 . Soluble solids concentrations at harvest increased from $5.4 \%$ to $7.0 \%$ during this time, and titratable acidity ranged between $1.8 \%$ and $2.0 \%$. After ripening kiwifruit to a flesh firmness of 2 to 3 pounds-force (9 to 13.5 Newtons), average soluble solids concentration and titratable acidity varied between $11.8 \%$ and $13.3 \%$, and $0.5 \%$ and $1.2 \%$, respectively. Vineyard D fruit had the highest dry matter on the first harvest date (Sept. 15); dry matter was the same in the three vineyards for the rest of the harvest dates.

The minimum quality index of dry matter greater than or equal to $15.1 \%$ was observed on the first harvest date (Sept. 15) for the three Sacramento Valley vineyards. However, none of the fruit from these vineyards reached the minimum quality index for soluble solids concentration until the last two harvest dates. After ripening, fruit from vineyard D had soluble solids concentrations greater than or equal to $12.5 \%$ on all harvest dates, except the third harvest date. Fruit from the other two vineyards had ripe soluble solids concentrations greater than or equal to $12.5 \%$ by the fourth harvest date, while titratable acidity remained less than or equal to $1.2 \%$.
2007 samples. In the 2007 growing season, average dry matter at harvest $(16.1 \%$ to $16.8 \%$ ) and soluble solids concentrations at harvest (5.6\% to $7.7 \%$ ) and when ripe $(13.3 \%$ to $14.5 \%)$ of kiwifruit grown in the San Joaquin Valley vineyards increased consistently between Sept. 27 and Oct. 22 . (We did not measure titratable acidity at harvest or after ripening on fruit from these vineyards.) Vineyard A fruit had dry matter consistently higher on all harvest dates than fruit from vineyards $B$ and C. Vineyard C fruit had consistently the lowest dry matter and harvest and ripe soluble solids concentrations on all harvest dates, but harvest soluble solids concentrations were similar in the three vineyards on the fourth harvest date (Oct. 22). Fruit from vineyard A met the minimum quality index for dry matter and soluble solids concentration by the first (Sept. 27) harvest date, and fruit from vineyard B met it by the second (Oct. 4) harvest date. Vineyard $C$ fruit did not meet the minimum quality index for dry matter on any harvest date, and it met the minimum quality index for soluble solids concentration on the last harvest date (Oct. 22). After ripening, vineyards A and $B$ fruit met the minimum quality index for soluble solids concentration on the first harvest date (Sept. 27), while vineyard $C$ fruit met that value by the third harvest (Oct. 11).

Similar results were observed in the three vineyards in the Sacramento Valley during 2007, although the values were higher compared with those in the San Joaquin Valley. Also, titratable acidity 
decreased from harvest to ripening, with a smaller decrease in 2006 than in 2007.

Seasonal variation. After two consecutive growing seasons, the data suggest that variation in dry matter and other fruit quality attributes depends on harvest time (Crisosto et al. 2007, 2009; Crisosto, Garibay et al. 2008), growing area (Crisosto et al. 2007, 2009; Crisosto, Garibay et al. 2008), vineyard and year. For these six vineyards, dry matter variability was higher among vineyards than between seasons, and ripe titratable acidity variability was low among vineyards but high between seasons.

Our 6-year California kiwifruit quality attribute survey demonstrated that dry matter and ripe titratable acidity were highly variable among seasons, with ripe titratable acidity values varying more among seasons than dry matter (fig. 1).

\section{Proposed kiwifruit quality index}

Based on our studies, we propose a minimum quality index of dry matter greater than or equal to $16.1 \%$ when ripe titratable acidity is greater than or equal to $1.2 \%$, and $15.1 \%$ when ripe titratable acidity is less than $1.2 \%$, to maximize consumer satisfaction.

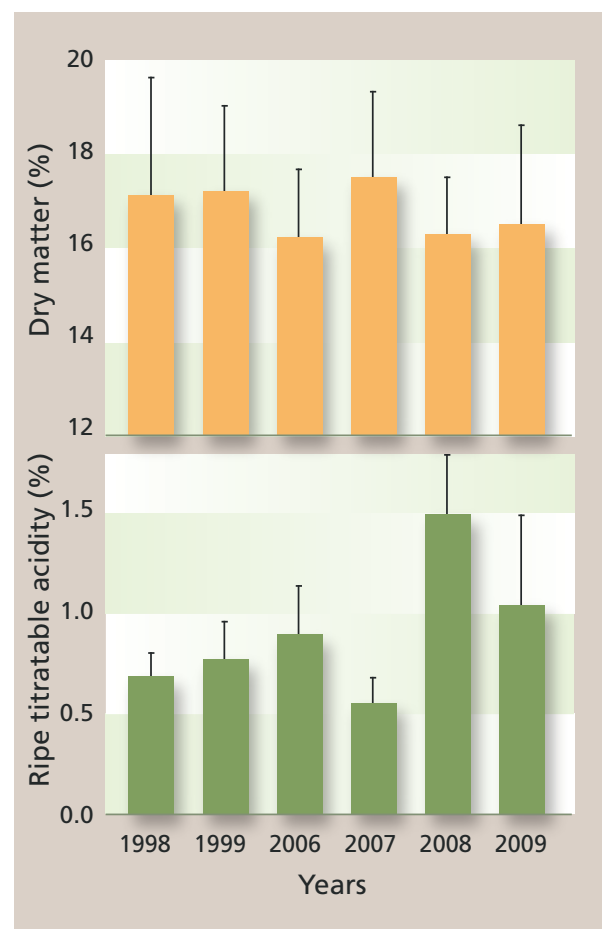

Fig. 1. Seasonal variation in dry matter and ripe titratable acidity of Hayward kiwifruit. Vertical bars on mean values indicate standard deviations.
During the six growing seasons of harvest and cold-storage sample collection from California vineyards $(n=3,156)$, dry matter ranged from $11 \%$ to $22 \%$ with an average of $17.1 \%$ and a standard deviation of $1.6 \%$ (fig. 2A). Of these samples, $76.2 \%$ and $90.7 \%$ exceeded our proposed minimum quality indexes of dry matter greater than or equal to $16.1 \%$ and $15.1 \%$, respectively. In the imported kiwifruit collected in 2009 and $2010(n=48)$, dry matter ranged between $14 \%$ and $19 \%$, with an average of $16.0 \%$ and a standard deviation of $1.4 \%$ (fig. 2B). Of these imported samples, $37.5 \%$ and $77.1 \%$ exceeded our proposed minimum quality indexes of dry matter greater than or equal to $16.1 \%$ and $15.1 \%$, respectively.

Although the influence of ripe titratable acidity on consumer acceptance has been previously documented (Crisosto and Crisosto 2001; Rossiter et al. 2000), the direct impact of dry matter and ripe titratable acidity together on kiwifruit acceptance (table 2), using single-fruit measurements, has not been previously reported. In our study, kiwifruit with high ripe titratable acidity $(\geq 1.2 \%)$ required high dry matter $(\geq 16.1 \%)$ for consumers to "like" the fruit; for kiwifruit with ripe titratable acidity less than $1.2 \%$, a minimum dry matter of $15.1 \%$ was adequate for consumer acceptance.

This effect of ripe titratable acidity may be explained by the fact that high dry matter is associated with sweetness (Burdon et al. 2004; Jordan et al. 2000), which may balance a sourness perception, as reported in kiwifruit and mango (Harker et al. 2009; Malundo et al. 2001). When fruit is perceived to be less sour (ripe titratable acidity $<1.2 \%$ ), consumers are less demanding for high soluble sugars, or dry matter content, and they "like" kiwifruit with dry matter greater than or equal to $15.1 \%$.

Crisosto and Crisosto (2001) reported that total organic acid content, in terms of titratable acidity at harvest, was relatively stable across harvest seasons. Similar to that study, we noticed a decrease in ripe titratable acidity between harvest and ripening in both years of our fruit quality attributes survey (data not shown). In 2006, titratable acidity decreased $54 \%$ from harvest to ripening, and in 2007 it decreased $70 \%$. The high ripe titratable acidity observed during the in-store consumer test in the 2008 growing season may explain

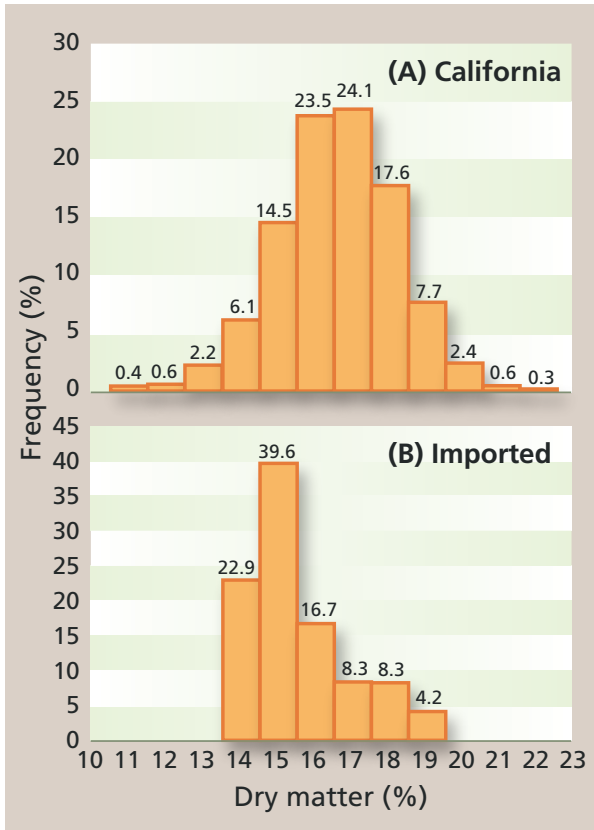

Fig. 2. Dry matter distribution of Hayward kiwifruit for (A) California harvest and coldstorage samples in 1998, 1999, 2006, 2007, 2008 and 2009 growing seasons $(n=3,156)$ and (B) imported samples collected from commercial cold-storage facilities and retail stores during the 2009 and 2010 U.S. low-availability season (March to May and August to November) $(n=48)$.

the high dry matter level (and indirectly the ripe soluble solids concentration) needed for consumers to like the kiwifruit when ripe titratable acidity was greater than or equal to $1.2 \%$ (table 2 ).

Therefore, in terms of marketing, dry matter would be a more accurate tool than soluble solids concentration alone for controlling minimum quality at harvest, and for meeting export and import requirements. As only minor changes in dry matter occur during postharvest handling, kiwifruit with low consumer acceptance - either harvested early in the season or from potentially low-quality vineyards (dry matter $<15.1 \%$ ) - could be detected. In our study, differences in dry matter among kiwifruit sources remained constant throughout the cold-storage period. This lack of dry matter change is an advantage over the soluble solids concentration maturity index currently in place.

In some commodities, soluble sugars and organic acids (important components of dry matter) are reduced during cold storage because of respiratory activity. The kiwifruit's low metabolic respiration favors the maintenance of dry matter and soluble sugars, as well as a low water loss 
potential when fruit is kept at $32^{\circ} \mathrm{F}\left(0^{\circ} \mathrm{C}\right)$ and with relative humidity of $90 \%$ to $95 \%$. Kiwifruit's respiration rate is less than or equal to 2 milliliters carbon dioxide per kilogram per hour at $32^{\circ} \mathrm{F}\left(0^{\circ} \mathrm{C}\right)$, whereas the rates for other commodities, such as peach and apple, are about 1.5 and 3.0 times higher, respectively, at the same temperature (Ritenour et al. 1999).

Dry matter content should not be used as the sole index at harvest, since storage potential tests at different dry matter levels have not been investigated extensively. To assure long cold-storage potential, we recommend that the new dry matter quality index be used with the current harvest maturity index between $6.2 \%$ and $6.5 \%$ soluble solids concentration (a minimum of $6.2 \%$ is required to avoid flesh breakdown during long-term cold storage of 3 to 6 months).

Our proposed dry matter quality index would segregate out kiwifruit of low consumer quality either harvested early in

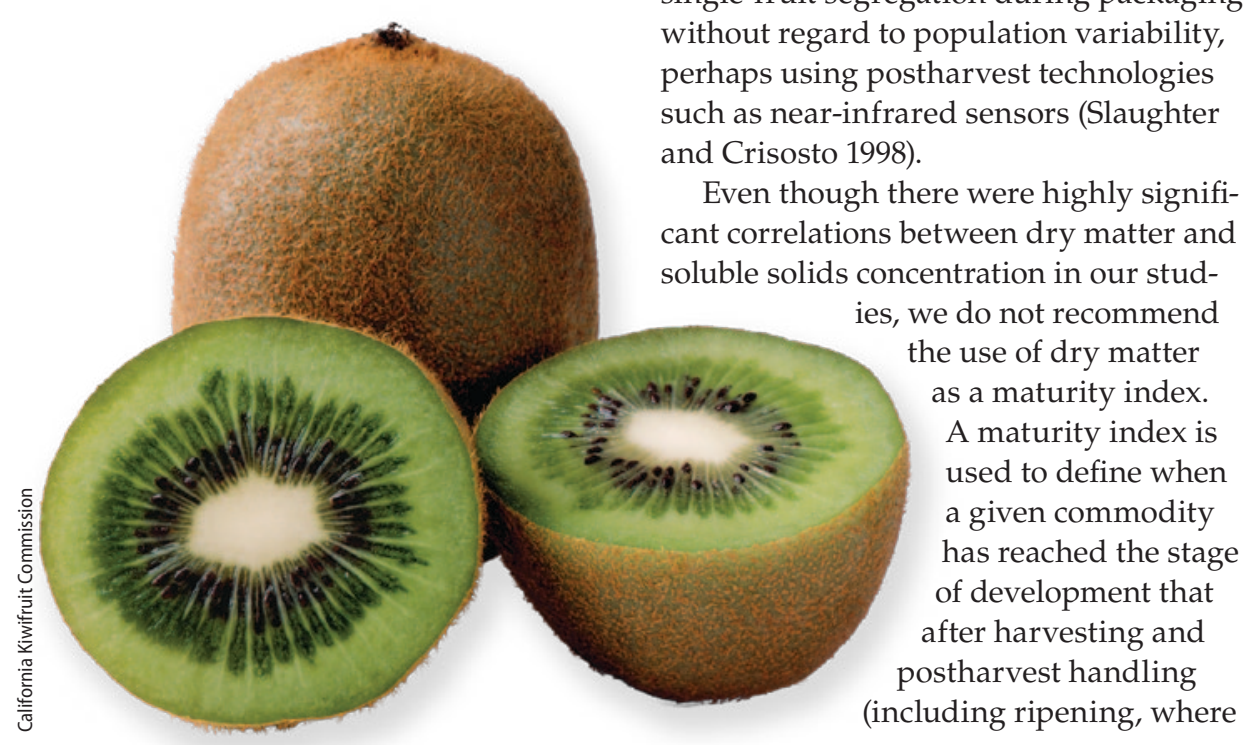

\section{References}

Beever DJ, Hopkirk G. 1990. Fruit development and fruit physiology. In: Warrington IJ, Wetson GC (eds.). Kiwifruit: Science and Management. Auckland, NZ: Ray Richards Pub. p 97-126.

Burdon J, McLeod D, Lallu N, et al. 2004. Consumer evaluation of Hayward kiwifruit of different at-harvest dry matter contents. Postharvest Biol Tech 34:245-55.

Crisosto CH, Crisosto GM. 2001. Understanding consumer acceptance of early harvested Hayward kiwifruit. Postharvest Biol Tech 22:205-13.

Crisosto CH, Garibay S, Hasey J, et al. 2008. Evaluating Kiwifruit Dry Weight. 2007 Research Report to California Kiwifruit Commission.

Crisosto CH, Hasey J, Cantin CM, et al. 2008. New kiwifruit dry weight protocol. UC Cooperative Extension Central Valley Postharvest Newsletter 17:11-5. the season or from low-quality vineyards. While the dry matter values may not be reached during early harvests (September, in California), some exceptions could be allowed depending on growing area, vineyard management and weather conditions in particular years, as suggested by other authors (Burdon et al. 2004; Crisosto and Crisosto 2001).

Our data indicated that there was strong variation from one season to the next in attributes such as dry matter, harvest and ripe soluble solids concentrations, and harvest and ripe titratable acidity. Among these attributes, ripe titratable acidity had the lowest variability within a season. These differences in kiwifruit quality attributes from year to year, coupled with consumer acceptance, highlight the need to segregate kiwifruit based on consumer acceptance. Because the proposed minimum dry matter quality index is based on single-fruit measurements and consumer acceptance, it would allow single-fruit segregation during packaging without regard to population variability, perhaps using postharvest technologies such as near-infrared sensors (Slaughter nd Crisosto 1998).

Even though there were highly significant correlations between dry matter and soluble solids concentration in our stud-

ies, we do not recommend as a maturity index. A maturity index is used to define when a given commodity has reached the stage of development that after harvesting and including ripening, where
Crisosto CH, Hasey J, Crisosto G, Garner D. 2009. Evaluating Kiwifruit Dry Weight. 2008 Research Report to California Kiwifruit Commission.

Crisosto CH, Hasey J, Slaughter D, Crisosto G. 2007. Evaluating Dry Weight Sensors to Segregate Kiwifruit According to Consumer Acceptance. 2006 Research Report to California Kiwifruit Commission.

Crisosto CH, Mitchell FG. 2002. Kiwifruit. In: Kader AA (ed.). Postharvest Technology of Horticultural Crops. UC ANR Pub 3311. Oakland, CA. p 371-4.

Harker FR, Carr BT, Lenjo M, et al. 2009. Consumer liking for kiwifruit flavour: A meta-analysis of five studies on fruit quality. Food Qual Prefer 20:30-41.

Jordan RB, Walton EF, Klages KU, Seelye RJ. 2000. Postharvest fruit density as an indicator of dry matter and ripened soluble solids of kiwifruit. Postharvest Biol Tech 20:163-73. required) its quality will be at least the minimum acceptable to the consumer. This maturity index may be an enforced standard; a quality index is a guide that is used voluntarily to assure a certain level of quality. Previously published information demonstrated that immature or overmature kiwifruit, with maturity based on harvest soluble solids concentration, can develop senescent breakdown - the breakdown of tissues or the development of granular, mealy or soaked tissues during long cold-storage periods (Crisosto and Crisosto 2001).

Our studies demonstrate that dry matter is a reliable consumer quality index, but not a reliable maturity index, so harvest decisions should still include harvest soluble solids concentration and firmness to protect kiwifruit in long-term storage or marketing conditions. Studies are needed to understand the potential limitations of dry matter in predicting long-term cold-storage performance.

G.M. Crisosto is Specialist, Department of Plant Sciences, UC Davis; J. Hasey is Farm Advisor, UC Cooperative Extension, Sutter-Yuba Counties; J.A. Zegbe is Visiting Scientist, Instituto Nacional de Investigaciones Forestales, Agrícolas y Pecuarias, Campo Experimental Zacatecas, Mexico; and C.H. Crisosto is UC Cooperative Extension Postharvest Physiologist, Department of Plant Sciences, UC Davis.

This research was funded by the California Kiwifruit Commission and USDA NIFA grant \#2009-51181-05783. Part of the data analysis was undertaken during J.A. Zegbe's sabbatical leave, supported by the Consejo Nacional de Ciencia y Tecnología (CONACYT, México) No. Ref. 94173, Instituto Nacional de Investigaciones Forestales, Agrícolas y Pecuarias (INIFAP, México) and Universidad Autónoma de Zacatecas (México).
Lawless HT, Heymann H. 2010. Acceptance testing. In: Lawless HT, Heymann H (eds.). Sensory Evaluation of Food: Principles and Practices. New York, NY: Springer. p 325-48. Malundo TMM, Shewfelt RL, Ware GO, et al. 2001. Sugars and acids influence flavor properties of mango (Mangifera indica). J Am Soc Hort Sci 126:115-21.

Ritenour MA, Crisosto CH, Garner DT, et al. 1999. Temperature, length of cold storage and maturity influence the ripening rate of ethylene-preconditioned kiwifruit. Postharvest Biol Tech 15:107-15.

Rossiter KL, Young H, Walker SB, et al. 2000. The effects of sugars and acids on consumer acceptability of kiwifruit. J Sens Stud 15:241-50.

Slaughter DC, Crisosto CH. 1998. Nondestructive internal quality assessment of kiwifruit using near-infrared spectroscopy. Seminars in food analysis 3:131-40. 